Available online at: http://journal.unj.ac.id

Jurnal

Pensil

Pendidikan Teknik Sipil

Journal homepage: http://journal.unj.ac.id/unj/index.php/jpensil/index

\title{
STUDI KEPUASAN PENGGUNA LULUSAN PROGRAM STUDI PENDIDIKAN TEKNIK BANGUNAN UNIVERSITAS NEGERI JAKARTA DI BIDANG KEPENDIDIKAN
}

\section{STUDY OF USER SATISFACTION GRADUATES OF BUILDING ENGINEERING EDUCATION STUDY PROGRAM UNIVERSITAS NEGERI JAKARTA IN THE EDUCATION SECTOR}

\author{
Nida Zafarina \\ Universitas Negeri Jakarta, Jalan Rawamangun Muka, Jakarta Timur, DKI Jakarta 13120, \\ Indonesia \\ nzafarinaazahra@gmail.com
}

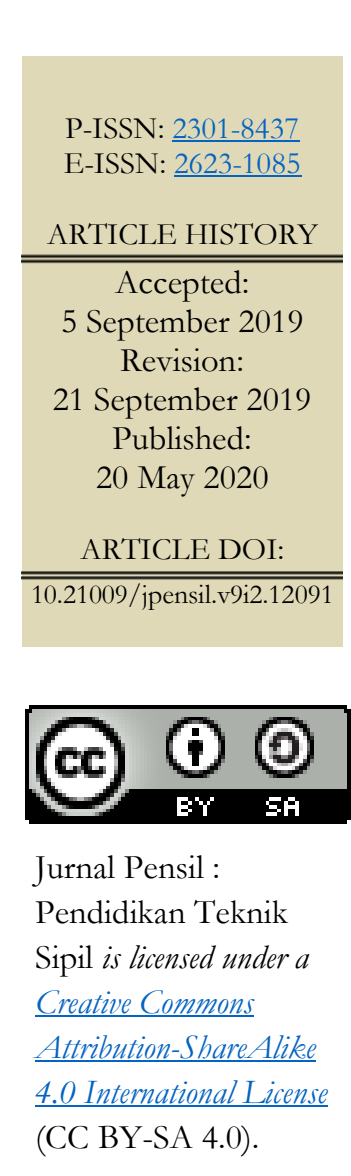

Abstrak

Penelitian ini bertujuan untuk mengetahui profil lulusan Program Studi Pendidikan Teknik Bangunan Universitas Negeri Jakarta dalam bidang pekerjaan pendidikan sebagai guru dan untuk mengetahui kepuasan pengguna lulusan terhadap kinerja lulusan. Penelitian ini dilakukan pada bulan Maret hingga Juli 2019. Penelitian ini dilakukan pada lulusan Program Studi Pendidikan Teknik Bangunan Universitas Negeri Jakarta. Penelitian ini menggunakan metode kuantitatif berupa angka dan teknik pengumpulan data dengan cara menyebarkan kuesioner kepada lulusan melalui Google Form untuk mempermudah mendapatkan jawaban dan menyebarkan kuesioner secara langsung kepada pengguna lulusan untuk mengetahui kinerja lulusan Pendidikan Teknik Bangunan. Sampel pada penelitian ini adalah 23 lulusan yang bekerja di bidang pendidikan sebagai guru. Hasil yang diperoleh dari studi lulusan Pendidikan Teknik Bangunan 69,6\% bekerja di SMK, 52\% menyatakan bahwa pekerjaan saat ini sesuai dengan bidang ilmu yang diperoleh selama perkuliahan. Pada kepuasan pengguna wisuda penilaian kinerja lulusan sesuai dengan kompetensi lulusan membuktikan bahwa kompetensi pedagogik $(40 \%)$ berada pada kategori sedang, kompetensi kepribadian (62\%) berada pada kategori tinggi, kompetensi profesional $(62 \%)$ berada pada kategori tinggi, dan kompetensi sosial (42\%) pada kategori sedang. Hasil penelitian ini menunjukkan bahwa pengguna lulusan merasa puas dengan kinerja lulusan PTB UNJ pada kompetensi kepribadian dan kompetensi profesional. Sedangkan, pengguna lulusan belum puas dengan kompetensi pedagogik dan sosial.

Kata kunci: kepuasan pengguna lulusan, standar kompetensi lulusan, pekerjaan bidang pendidikan 


\begin{abstract}
This research aims to determine the profile of graduates of Building Engineering Education Study Program of Universitas Negeri Jakarta in the field of educational work as a teacher and to determine the satisfaction of graduate users with graduate performance. This research was conducted from March to July 2019.

The research was conducted on graduates of the Building Engineering Education Study Program at Universitas Negeri Jakarta. This research used quantitative methods in the form of numbers and data collection techniques by distributing questionnaires to graduates through Google Form to make it easier to get answers and distribute questionnaires directly to graduate users to find out the performance of graduates of Education Building technique. The sample in this study were 23 graduates who worked in the field of education as teachers.

The results obtained from the study of graduates of Building Engineering Education graduates $69.6 \%$ graduates work in SMK, 52\% stated that the current job is in accordance with the field of science obtained during college. On the Graduation User Satisfaction of the graduate performance appraisal in accordance with the Competence of graduates proved that pedagogical competence (40\%) was in the medium category, personality competency (62\%) was in the high category, professional competency (62\%) was in the high category, and social competency (42\%) was in the medium category. The results of this study indicate that graduates are satisfied with the performance of PTB UNJ graduates on personal competence and professional competence. Meanwhile graduate users have not been satisfied with pedagogic and social competencies.
\end{abstract}

Keywords: graduation user satisfaction, graduates competency standards, educational work. field

\section{Pendahuluan}

Universitas merupakan lembaga ilmiah yang mempunyai peran sangat penting dalam mencerdaskan bangsa dan menyelenggarkan program pendidikan dalam sejumlah disiplin ilmu pengetahuan. Universitas merupakan Perguruan Tinggi yang memiliki beragam fakultas, dan program studi, serta dapat menyelenggarakan dua program pendidikan berbagai disiplin ilmu yaitu disiplin ilmu program pendidikan dan non pendidikan.

Universitas menghasilkan sumber daya berupa alumni atau mahasiswa yang telah menyelesaikan kuliahnya dan telah diwisuda. Alumni yang telah lulus akan melanjutkan hidupnya untuk bekerja. Oleh karena itu untuk menghasilkan alumni yang berkualitas dituntut untuk dapat mengembangkan potensi mahasiswa lebih kompeten agar lebih inovatif, kreatif dan professional. Seberapa besar alumni perguruan tinggi mampu berkiprah dalam pembangunan sesuai relevansi pendidikannya dapat dilakukan upaya penelusuran terhadap lulusannya (tracer study).

Alumni merupakan produk dari suatu institusi pendidikan.Kualitas alumni menunjukkan kualitas dari institusi pendidikan tersebut. Untuk mengetahui kualitas lulusan yang dihasilkan tidak cukup hanya melihat output-nya saja, misalnya dari kemampuan penguasaan pengetahuan, keterampilan dan sikap formal yang diwujudkan dalam Indeks Prestasitetapi harus pula dideteksi dari outcomenya, yaitu seberapa besar lulusannya dapat terserap dalam dunia kerja.

Kompetensi dapat diakumulasikan dalam suatuindividu dan mewakili kapasitas untuk tampil di beberapa titik masa depan. Pada dasarnya, definisi ini berhubungan dengan bertahan lama karakteristik yang 
dimiliki oleh seorang individu yang, dalam kondisi normal, harus menghasilkan pekerjaan yang dapat diterima atau unggul kinerja (Hodges \& Burchell, 2003, pp. 1622). Dalam konteks tempat kerja, kompetensi adalah kombinasi dari keterampilan kognitif (pengetahuan teknis, keahlian \& kemampuan), dan karakteristik pribadi atau perilaku (prinsip, sikap, nilai dan motif), yang merupakan fungsi dari suatu kepribadian individu. Performa yang sukses, sementara tergantung pada sejumlah faktor, akan membutuhkan kehadiran dari kedua komponen.

Perguruan tinggi sebagai lembaga pendidikan melaksanakan fungsi Tridharma Perguruan Tinggi, yaitu pendidikan, penelitian, dan pengabdian kepada masyarakat serta mengelola IPTEK. Universitas Negeri Jakarta (UNJ) merupakan salah satu perguruan tinggi di Indonesia yang mencetak lulusan tenaga kependidikan, sesuai dengan visi dan misi UNJ. Semakin berkembangnya zaman dan semakin pesatnya kemajuan teknologi yang menuntut sumber daya manusia yang berkualitas dalam kinerja pada bidangnya masing-masing. Hal ini menyebabkan semakin dibutuhkannya tenaga kerja yang profesional sesuai keahlian yang dimiliki oleh alumni perguruan tinggi.

Universitas Negeri Jakarta (UNJ) merupakan suatu lembaga perguruan tinggi yang telah terakreditasi oleh BAN PT. Berdasarkan No. SK 4333/SK/BANPT/Ak-INV/PT/XI/2017 akreditasi yang dimiliki UNJ saat ini adalah B. Salah satu yang menjadi misi dari UNJ adalah menyiapkan tenaga akademik dan/atau profesional yang bermutu, berjiwa kepemimpinan, bertanggung jawab dan mandiri dibidang pendidikan dan non kependidikan guna menghadapi berbagai tantangan dan persaingan dimassa depan. UNJ memiliki banyak sekali program studi didalamnya, dan salah satunya adalah Program Studi Pendidikan Teknik Bangunan (PTB). PTB memiliki visi menjadi suatu lembaga yang menghasilkan sarjana pendidikan yang profesional, unggul, bertaqwa, berjiwa kebangsaan, dan berwawasan global serta berjiwa wirausaha yang sinergi dengan bidang non kependidikan teknik bangunan (Kementerian Riset, Teknologi, dan Pendidikan, 2015).

Profil lulusan yang diharapkan Program Studi Pendidikan Teknik Bangunan adalah; (1) menghasilkan tenaga guru bidang keahlian Teknik Bangunan yang mampu mengembangkan sistem pengajaran bidang keahlian Teknik Bangunan di SMK dan pendidikan formal dan pendidikan non formal yang setingkat dengan itu; (2) menghasilkan tenaga yang bisa bekerja dibidang jasa konstruksi yang relevan dengan keahliannya dalam bidang Teknik Bangunan; (3) menghasilkan lulusan yang bisa berwirausaha dengan bekal ilmu Teknik Bangunan (Kementerian Riset, Teknologi, dan Pendidikan, 2015).

Guru adalah pendidik profesional dengan tugas utama mendidik, mengajar, membimbing, mengarahkan, melatih, menila, dan mengevaluasi peserta didik pada pendidikan anak usia dini jalur pendidikan formal, pendidikan dasar, dan pendidikan menengah (Depdiknas, 2005). Keberadaan guru profesional merupakan salah satu persyaratan yang wajib dipenuhi guna meningkatakan kualitas pendidikan di Indonesia agar dapat bersaing dengan negara-negara maju lainnya. Hampir semua bangsa di dunia ini selalu mengembangkan kebijakan yang mendorong terciptanya guru yang kompeten dan berkualitas.

Guru profesional adalah guru yang mampu mengelola dirinya sendiri dalam melaksanakan tugas-tugasnya sehari-hari. Profesionalisme yang dimaksud oleh mereka adalah suatu proses yang bergerak dari tidah tahu menjadi tahu, dari tidak matang menjadi matang (Wahyudi, 2012), sedangkan menurut Glickman dalam Bafadal yang mengaskan bahwa seseorang akan bekerja secara profesional bilamana orang tersebut memiliki kemampuan profesional bilamana memilih kemampuan tinggi dan motivasi kerja tinggi.

Seorang guru profesional, memiliki kemampuan atau kompetensi yaitu 
seperangkat kemampuan sehingga dapat mewujudkan kinerja profesionalnya. Kemampuan yang perlu dimiliki guru dalam melaksanakan tugas pokoknya ialah kemampuan pedagogik (kemampuan mengelola pembelajaran), kemampuan kepribadian (kemampuan yang dewasa), kemampuan profesional (kemampuan penguasaan materi yang luas), dan kemampuan sosial (kemampuan untuk berkomunikasi) (Alma, 2009).

Studi Penelusuran (Tracer Study) Lulusan Program Studi Pendidikan Teknik Bangunan FT UNJ Tahun Lulusan 20062011 menyatakan bahwa mayoritas pekerjaan lulusan Program Studi Pendidikan Teknik Bangunan bekerja dibidang non pendidikan sebagai tenaga staff teknik dibidang kontraktor, konsultan, dan dibidang ekonomi seperti perbankan dan wirausaha. Sebanyak 44 orang $(80 \%)$ bekerja dibidang non pendidikan sedangkan yang bekerja dibidang pendidikan berjumlah 11 orang (20\%) (Sari, 2015, pp. 79-84). Kesesuaian bidang pekerjaan lulusan Program Studi Pendidikan Teknik Bangunan dengan kompetensi lulusan yaitu 6 orang atau $10,91 \%$ dari 48 orang responden yang memiliki bidang pekerjaan yang berkaitan dengan teknik bangunan. Pendapatan yang diperoleh para lulusan sudah melebihi gaji Pegawai Negeri golongan III, walaupun terkadanglulusan Pendidikan Teknik Sipil UNJ dipandang sebelah mata oleh perusahaan-perusahaan swasta maupun perusahaan asing karena lulusan Pendidikan Teknik Sipil menyandang gelar sarjana Pendidikan (S.Pd).

Penelitian Mahendra (2012, pp. 1-20) yang membahas tentang "Studi Kepuasan Pengguna Lulusan Program Studi Pendidikan Teknik Bangunan Jurusan Teknik Sipil FT UNJ (Studi Kasus Pada Lembaga Pendidikan Formal Dan Non Formal se-Jabodetabek) tahun 2012, menyatakan bahwa tingkat kepuasan untuk kompetensi pedagogik dengan tingkat kesesuaian 79,83\% yang berarti cukup puas, untuk kompetensi kepribadian dengan tingkat kesesuaian $87,55 \%$ yang berarti puas, untuk kompetensi professional dengan tingkat kesesuaian $83,23 \%$ berarti puas, untuk kompetensi sosial dengan tingkat kesesuaian $87,38 \%$ yang berarti puas, dan untuk kompetensi kewirausahaan dengan tingkat kesesuaian $84,83 \%$ yang berarti puas dengan kompetensi yang dimiliki lulusan Program Studi Pendidikan Teknik Bangunan FT UNJ.

Fenomena lain berdasarkan penelitian dari Agustin (2017, pp. 1-5) yang membahas tentang "Analisis Keteserapan Lulusan Program Studi Pendidikan Teknik Bangunan Fakultas Teknik Universitas Negeri Jakarta Di Lapangan Pekerjaan", menunjukkan bahwa rata-rata waktu tunggu alumni $<3$ bulan dengan persentase $74,4 \%$. Jenis pekerjaan alumni yang sesuai dengan kompetensi lulusan di bidang pendidikan sebesar 7,70\% dan bidang non kependidikan sebesar 92,30\%dan rata-rata penghasilan atau gaji alumni pada pekerjaan pertama kurang dari 3jt sebesar 20,51\%. Sedangkan untuk penghasilan atau gaji alumni pada saat ini presentase terbesar yaitu $4 \mathrm{jt}-5 \mathrm{jt}$ sebesar $46,15 \%$.

Kompetensi profesional adalah kemampuan penguasaan materi pelajaran secara mendalam dan luas (Depdiknas, 2005). Untuk menerapkan kompetensi ini ke dalam pembelajaran, ada beberapa kriteria yang perlu diperhatikan oleh seorang guru yaitu: 1. Memahami tujuan pelajaran; 2. Mengenali karakteristik peserta didik; 3. Membuat tujuan pengajaran; 4. Mengenali subyek dan isi setiap materi; 5 . Mengembankan alat ukur awal; 6. Menyaring kegiatan-kegiatan belajar beserta sumbersumbernya; 7. Mengarahkan layanan-layanan yang mampu mendukung (dana, alat, jadwal) dan mengembangkan alat evaluasi belajar.

Berdasarkan uraian di atas, penelitian ini akan melakukan studi penelusuran pada lulusan mahasiswa program studi Pendidikan Teknik Bangunan selama kurun 2014 sampai dengan 2018 diharapkan dapat menjadi sumber informasi yang berguna tentang sosialisasi keberadaan peluang kerja bagi program studi Pendidikan Teknik Bangunan. 


\section{Metode Penelitian}

Metode penelitian yang dipilih bersifat deskriptif karena bertujuan untuk mendeskripsikan karakteristik variabelvariabel pada situasi tertentu. Penelitian deskriptif adalahpenelitian yang dilakukan untuk mengetahui keberadaan variabel mandiri, baik hanya pada satu variabel atau lebih tanpa membuat perbandingan atau menghubungkan dengan variabel lainnya Variabel mandiri adalah variabel yang berdiri sendiri, bukan variabel independen (Sugiyono, 2012).

Pengumpulan data dan informasi berupa data kuantitatif yang berbentuk angka dan teknik pengambilan data dengan cara survey. Survey adalah metode penelitian deskriptif yang dilakukan dengan mekanisme terjun langsung dilapangan dengan menyebarkan angket atau kuesioner kepada responden. Penyebaran ini bertujuan langsung untuk mencari masalah, untuk mengumpulkan informasi dan fakta yang sebenarnya terjadi dilapangan.

\section{Hasil Penelitian dan Pembahasan}

Hasil Penelitian Penelusuran Lulusan

Berdasarkan hasil penelitian terdapat 23 responden yang merupakan lulusan Program Studi S1 Pendidikan Teknik Bangunan Universitas Negeri Jakarta bekerja di bidang kependidikan (guru). Dibawah ini jumlah data responden lulusan:

Tabel 1. Jumlah Responden Lulusan

\begin{tabular}{cc}
\hline Tahun lulusan & Jumlah responden (orang) \\
\hline$<2014$ & 13 \\
2015 & 2 \\
2016 & 3 \\
2017 & 2 \\
$>2018$ & 3 \\
\hline
\end{tabular}

(Sumber: Data prodi, 2018)
Untuk mengetahui informasi tentang lulusan, peneliti juga menggali data mengenai bidang pekerjaan, lama masa tunggu, cara memperoleh pekerjaan, status pekerjaan, gaji atau penghasilan dan kesesuaian bidang pekerjaan.

\section{Bidang Pekerjaan}

Dibawah ini jumlah responden menurut bidang pekerjaan :

Tabel 2. Bidang Pekerjaan

\begin{tabular}{lc}
\hline \multicolumn{1}{c}{ Profesi } & $\begin{array}{c}\text { Jumlah responden } \\
\text { (orang) }\end{array}$ \\
\hline Guru SMK & 16 \\
Guru SMA & 1 \\
Guru SD & 3 \\
Guru lainnya (privat) & 3 \\
\hline \multicolumn{1}{c}{ Total } & 23 \\
\hline
\end{tabular}

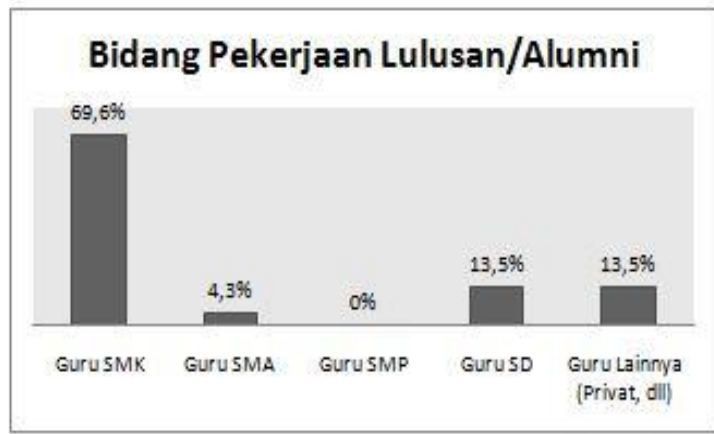

Gambar 1. Bidang Pekerjaan Alumni

Berdasarkan hasil gambar diatas menunjukan bahwa 69,6\% dari responden adalah lulusan yang mengajar di SMK, 13,5\% dari responden mengajar di SD dan guru privat, serta $4,3 \%$ responden mengajar di SMA.

\section{Lama Masa Tunggu Lulus Hingga Mendapatkan Pekerjaan \\ Berdasarkan hasil penelitian menunjukan bahwa lama masa tunggu lulusan untuk mendapatkan pekerjaan pertama dapat dilihat dari grafik berikut:}




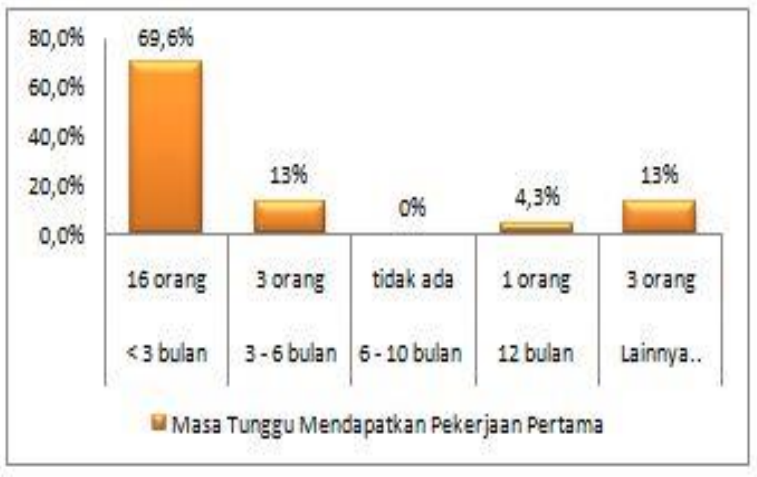

Gambar 2. Gambar 2 Lama Masa Tunggu

Berdasarkan gambar diatas menunjukan bahwa $69.9 \%$ dari responden lulusan mendapatkan pekerjaan kurang dari tiga bulan.

\section{Cara Memperoleh Pekerjaan}

Dibawah ini adalah cara yang dilakukan oleh lulusan memperoleh pekerjaan:

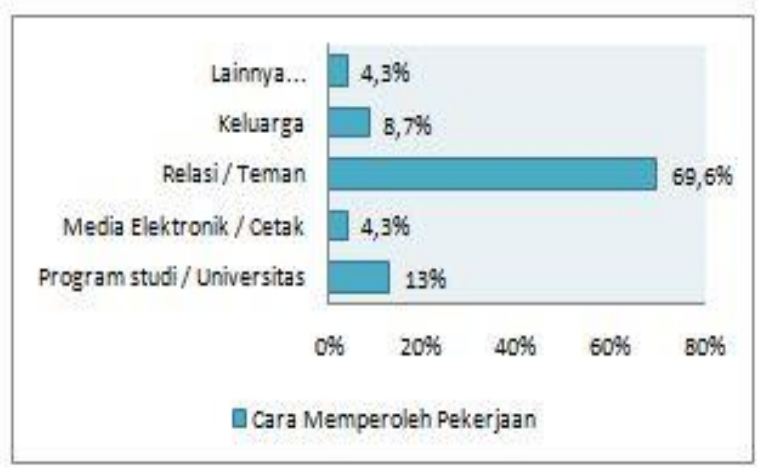

Gambar 3. Cara Memperoleh Pekerjaan

Berdasarkan Gambar 3 menunjukan bahwa $69,6 \%$ dari responden mendapatkan informasi pekerjaan lebih banyak dari relasi atau teman.

\section{Status Pekerjaan}

Dari hasil penelitian mengenai status pekerjaan dari responden lulusan 69,6\% masih berstatus pegawai tidak tetap.

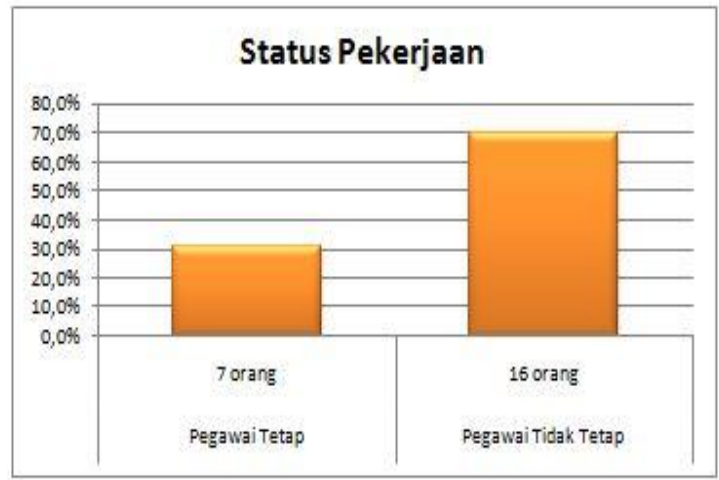

Gambar 4. Status Pekerjaan

\section{Pendapatan/Gaji}

Tabel 3 menunjukan bahwa pendapatan/gaji yang diperoleh lulusan Program Studi Pendidikan Teknik Bangunan di dunia pendidikan. Menunjukan bahwa 47,8\% dari responden memperoleh penghasilan $\mathrm{Rp}$. 3.500.000 - Rp. 4.500.000.

Tabel 3. Pendapatan/Gaji

\begin{tabular}{cc}
\hline Profesi & $\begin{array}{c}\text { Jumlah responden } \\
\text { (orang) }\end{array}$ \\
\hline$>\operatorname{Rp} 4.500 .000$ & 8 \\
Rp $3.500 .000-\operatorname{Rp~} 4.500 .000$ & 11 \\
Rp $2.500 .000-\operatorname{Rp~} 3.500 .000$ & 1 \\
$\operatorname{Rp~} 1.500 .000-\operatorname{Rp~} 2.500 .000$ & 3 \\
$<\operatorname{Rp~} 1.500 .000$ & 0 \\
\hline
\end{tabular}

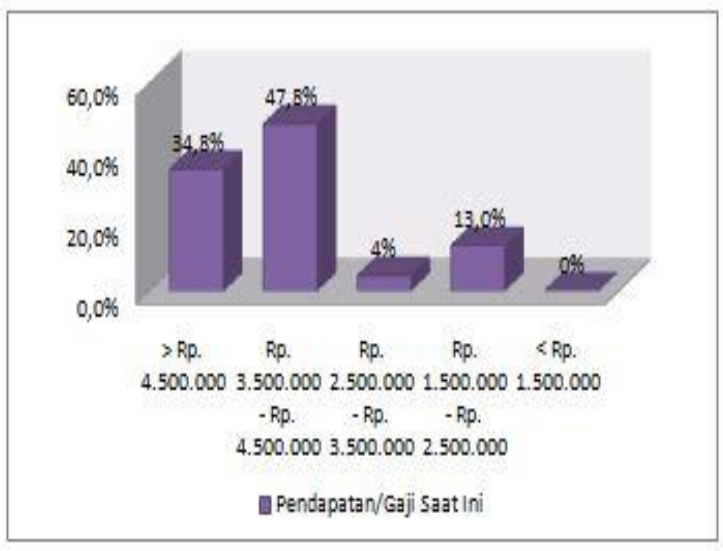

Gambar 5. Pendapatan/Gaji 


\section{Kesesuaian Bidang Pekerjaan}

Mengenai kesesuian bidang pekerjaan menunjukan bahwa 52.2\% dari responden bekerja dibidang pendidikan yang sesuai dengan bidang ilmu yang dimiliki yaitu Prodi Pendidikan Teknik Bangunan.

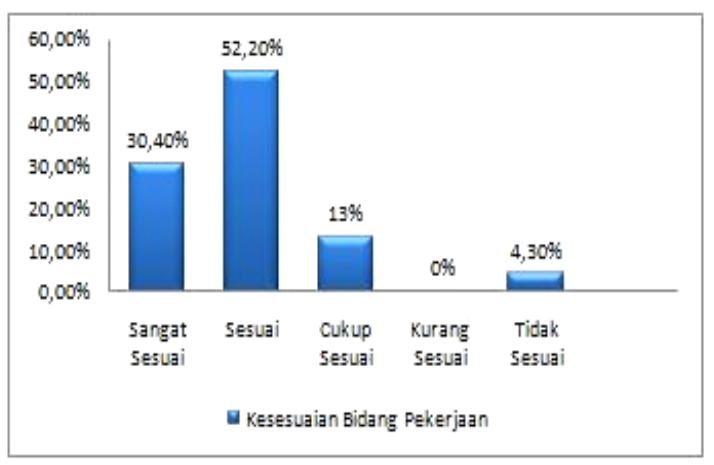

\section{Gambar 6. Kesesuaian Bidang Pekerjaan}

\section{Hasil Penelitian Kepuasan Pengguna} Lulusan

Untuk mengetahui kompetensi penilaian kinerja oleh pengguna lulusan di ukur berdasarkan yaitu kompetensi pedagogik, kepribadian, profesional, dan sosial. Data yang diperoleh melalui pengisian kuesioner penelitian adalah sebagai berikut :

\section{Kompetensi Pedagogik}

Kompetensi Pedagogik memiliki sub indikator perencanaan pembelajaran, pengelolaan pembelajaran, penguasaan bidang ilmu, evaluasi pembelajaran, dan inisiatif dalam bekerja .

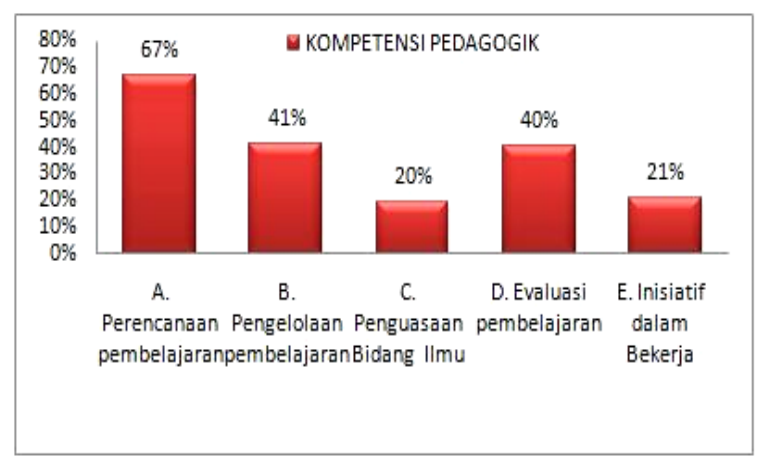

Gambar 7. Grafik Kepuasan Pengguna Lulusan pada Kompetensi Pedagogik
Tabel 4. Persentase Kepuasan Pengguna Lulusan Terhadap Kompetensi Pedagogik

\begin{tabular}{lccccc}
\hline $\begin{array}{c}\text { Kemampuan } \\
\text { yang diuji }\end{array}$ & $\begin{array}{c}\text { Skor } \\
\mathbf{( F )}\end{array}$ & $\begin{array}{c}\text { Skor } \\
\text { Maks } \\
\text { (N) }\end{array}$ & F/N & $\begin{array}{c}\text { Persen- } \\
\text { tase } \\
\mathbf{( \% )}\end{array}$ & Ket. \\
\hline $\begin{array}{l}\text { Perencanaan } \\
\text { pembelajaran }\end{array}$ & 258 & 384 & 0.67 & 67 & Tinggi \\
$\begin{array}{l}\text { Pengelolaan } \\
\text { pembelajaran }\end{array}$ & 158 & 384 & 0.41 & 41 & Sedang \\
$\begin{array}{l}\text { Penguasaan } \\
\text { bidang ilmu }\end{array}$ & 75 & 384 & 0.20 & 20 & Rendah \\
$\begin{array}{l}\text { Evaluasi } \\
\text { pembelajaran }\end{array}$ & 154 & 384 & 0.40 & 40 & Sedang \\
$\begin{array}{l}\text { Inisiatif } \\
\text { dalam bekerja }\end{array}$ & 79 & 384 & 0.21 & 21 & Rendah \\
\hline
\end{tabular}

Berdasarkan Tabel 4 menunjukan bahwa kepuasan pengguna terhadap lulusan dalam kompetensi pedagogik pada perencanaan pembelajaran memiliki penilaian $67.7 \%$ yang berarti tingkatan kepuasan pengguna ada dilevel "Tinggi".

\section{Kompetensi Kepribadian}

Kompetensi Kepribadian memiliki sub indikator sikap, keteladanan dan etika.

Tabel 5. Persentase Kepuasan Pengguna Lulusan Terhadap Kompetensi Kepribadian

\begin{tabular}{lccccc}
\hline $\begin{array}{c}\text { Kemampuan } \\
\text { yang diuji }\end{array}$ & $\begin{array}{c}\text { Skor } \\
\text { (F) }\end{array}$ & $\begin{array}{c}\text { Skor } \\
\text { Maks } \\
(\mathbf{N})\end{array}$ & F/N & $\begin{array}{c}\text { Persen- } \\
\text { tase } \\
\mathbf{( \% )}\end{array}$ & Ket. \\
\hline Sikap & 238 & 384 & 0.62 & 62 & Tinggi \\
Keteladanan & 229 & 384 & 0.60 & 60 & Tinggi \\
Etika & 254 & 384 & 0.66 & 66 & Tinggi \\
\hline
\end{tabular}

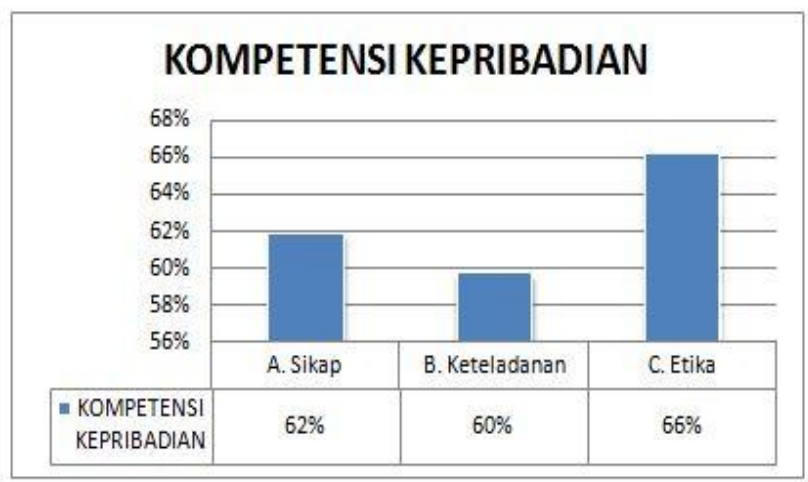

Gambar 8. Grafik Kepuasan Pengguna Lulusan pada Kompetensi

Kepribadian

Studi Kepuasan Pengguna Lulusan... 
Berdasarkan Tabel 5 menunjukan kepuasan pengguna lulusan terhadap kompetensi kepribadian memiliki nilai lebih dari $60 \%$, artinya ada dilevel "Tinggi".

\section{Kemampuan Profesional}

Kompetensi Profesional memiliki sub indikator kemampuan penguasaan materi, kemampuan penelitian dan penyusunan karya ilmiah, kemampuan pengembangan profesi, dan pemahaman terhadap wawasan dan landasan pendidikan.

Tabel 6. Persentase Kepuasan Pengguna Lulusan Terhadap Kompetensi Profesional

\begin{tabular}{lccccc}
\hline $\begin{array}{l}\text { Kemampuan } \\
\text { yang diuji }\end{array}$ & $\begin{array}{c}\text { Skor } \\
\text { (F) }\end{array}$ & $\begin{array}{c}\text { Skor } \\
\text { Maks } \\
\text { (N) }\end{array}$ & F/N & $\mathbf{( \% )}$ & Ket. \\
\hline $\begin{array}{l}\text { Kemampuan } \\
\text { penyusunan } \\
\text { materi }\end{array}$ & 179 & 384 & 0.47 & 47 & Sedang \\
\hline $\begin{array}{l}\text { Kemampuan } \\
\text { penelitian dan } \\
\text { penyusunan } \\
\text { karya ilmiah }\end{array}$ & 242 & 384 & 0.63 & 63 & Tinggi \\
\hline $\begin{array}{l}\text { Kemampuan } \\
\text { pengembanga } \\
\text { n profesi }\end{array}$ & 238 & 384 & 0.62 & 62 & Tinggi \\
\hline $\begin{array}{l}\text { Pemahaman } \\
\text { terhadap } \\
\text { wawasan dan } \\
\text { landasan } \\
\text { pendidikan }\end{array}$ & 246 & 384 & 0.64 & 64 & Tinggi \\
\hline
\end{tabular}

\begin{tabular}{|c|c|c|c|c|}
\hline $70 \%$ & \multirow{5}{*}{$47 \%$} & \multirow[t]{5}{*}{$63 \%$} & \multirow[t]{5}{*}{$62 \%$} & \multirow[t]{5}{*}{$64 \%$} \\
\hline $\begin{array}{l}60 \% \\
50 \%\end{array}$ & & & & \\
\hline $40 \%$ & & & & \\
\hline $30 \%$ & & & & \\
\hline $10 \%$ & & & & \\
\hline & $\begin{array}{l}\text { A. Kemampuan } \\
\text { penguasaan materi }\end{array}$ & $\begin{array}{l}\text { B. Kemampuan } \\
\text { penelitian dan } \\
\text { penyusunan karya } \\
\text { ilmiah }\end{array}$ & $\begin{array}{c}\text { C. Kemampuan } \\
\text { pengembangan } \\
\text { profesi }\end{array}$ & $\begin{array}{l}\text { D. Pemahaman } \\
\text { terhadap wawasan } \\
\text { dan landasan } \\
\text { pendidikan }\end{array}$ \\
\hline & & $₫$ KOMPETENSI & DFESIONAL & \\
\hline
\end{tabular}

Gambar 9. Grafik Kepuasan Pengguna Lulusan pada Kompetensi Profesional

Pada Gambar 9 menunjukan bahwa kepuasan pengguna lulusan terhadap lulusan dalam kompetensi profesional lebih dari 60\% berada dilevel "Tinggi".

\section{Kompetensi Sosial}

Kompetensi Sosial memiliki sub indikator kemampuan bahasa asing secara lisan, kemampuan menulis dalam bahasa asing, interaksi guru dengan siswa, interaksi guru dengan kepala sekolah, interaksi guru dengan rekan kerja, interaksi guru dengan orang tua siswa, interaksi guru dengan masyarakat, mampu mengemukakan pendapat, berbicara didepan umum, kemampuan menyelesaikan masalah, dan kemampuan menerima saran dan memberikan saran.

Tabel 7. Persentase Kepuasan Pengguna Lulusan Terhadap Kompetensi

Sosial

\begin{tabular}{|c|c|c|c|c|c|}
\hline $\begin{array}{l}\text { Kemampuan } \\
\text { yang diuji }\end{array}$ & $\begin{array}{c}\text { Skor } \\
(\mathrm{F})\end{array}$ & $\begin{array}{c}\text { Skor } \\
\text { Maks } \\
\text { (N) }\end{array}$ & F/N & $(\%)$ & Ket. \\
\hline $\begin{array}{l}\text { Kemampuan } \\
\text { bahasa asing } \\
\text { secara lisan }\end{array}$ & 83 & 384 & 0.22 & 22 & $\begin{array}{c}\text { Renda } \\
\mathrm{h}\end{array}$ \\
\hline $\begin{array}{l}\text { Kemampuan } \\
\text { menulis dalam } \\
\text { bahasa asing }\end{array}$ & 79 & 384 & 0.21 & 21 & $\begin{array}{c}\text { Renda } \\
\mathrm{h}\end{array}$ \\
\hline $\begin{array}{l}\text { Interaksi guru } \\
\text { dengan siswa }\end{array}$ & 246 & 384 & 0.64 & 64 & Tinggi \\
\hline $\begin{array}{l}\text { Interaksi guru } \\
\text { dengan kepala } \\
\text { sekolah }\end{array}$ & 171 & 384 & 0.44 & 44 & Sedang \\
\hline $\begin{array}{l}\text { Interaksi guru } \\
\text { dengan rekan } \\
\text { kerja }\end{array}$ & 242 & 384 & 0.63 & 63 & Tinggi \\
\hline $\begin{array}{l}\text { Interaksi guru } \\
\text { dengan orang } \\
\text { tua siswa }\end{array}$ & 163 & 384 & 0.42 & 42 & Sedang \\
\hline $\begin{array}{l}\text { Interaksi guru } \\
\text { dengan } \\
\text { masyarakat }\end{array}$ & 171 & 384 & 0.44 & 44 & Sedang \\
\hline $\begin{array}{l}\text { Mampu } \\
\text { mengemukaka } \\
\text { n pendapat }\end{array}$ & 92 & 384 & 0.24 & 24 & $\begin{array}{c}\text { Renda } \\
\mathrm{h}\end{array}$ \\
\hline $\begin{array}{l}\text { Berbicara di } \\
\text { depan umum }\end{array}$ & 88 & 384 & 0.23 & 23 & $\begin{array}{c}\text { Renda } \\
\mathrm{h}\end{array}$ \\
\hline $\begin{array}{l}\text { Kemampuan } \\
\text { menyelesaikan } \\
\text { masalah }\end{array}$ & 96 & 384 & 0.25 & 25 & $\begin{array}{c}\text { Renda } \\
\mathrm{h}\end{array}$ \\
\hline $\begin{array}{l}\text { Kemampuan } \\
\text { menerima dan } \\
\text { memberikan } \\
\text { saran }\end{array}$ & 213 & 384 & 0.55 & 55 & Sedang \\
\hline
\end{tabular}




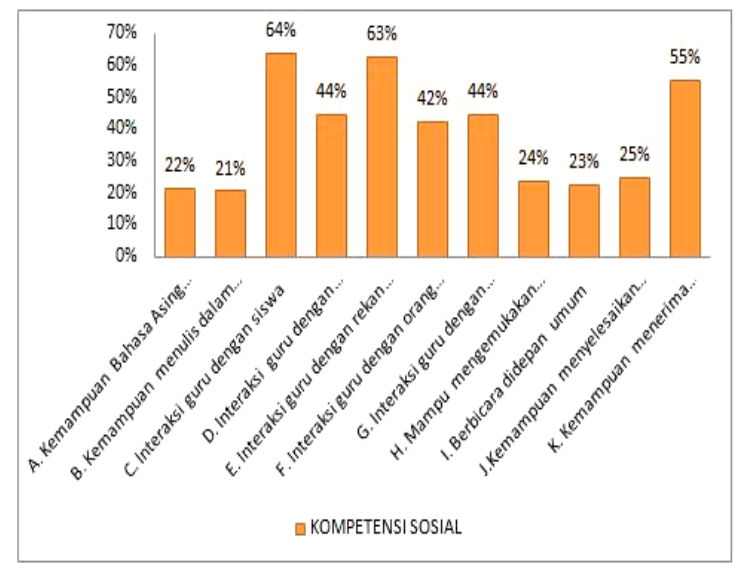

Gambar 10. Grafik kepuasan penguna lulusan pada kompetensi sosial

Pada Tabel 7 menunjukan bahwa kepuasan pengguna lulusan terhadap lulusan dalam kompetensi sosial lebih dari $60 \%$ yang berarti tingkatan kepuasan pengguna ada dilevel "Tinggi". Sedangkan yang perlu diperhatikan karena masih kurang dari 25\% berarti tingkatan kepuasan pengguna ada dilevel "Rendah".

\section{Pembahasan}

Berdasarkan studi penelusuran yang telah dilakukan kepada 23 responden lulusan PTB, umumnya bekerja sebagai guru di SMK. Hal ini sesuai dengan visi dan misi Pendidikan Teknik Bangunan yaitu "Menjadi lembaga yang menghasilkan sarjana Pendidikan Teknik Bangunan yang profesional, unggul, bertaqwa, berjiwa kebangsaan, dan berwawasan global serta berjiwa wirausaha yang sinergi dengan bidang kependidikan dan non kependidikan. (Kementerian Riset, Teknologi, dan Pendidikan, 2015).

Lama masa tunggu untuk mendapatkan pekerjaan kurang dari tiga bulan. Menurut Badan Akreditasi Nasional Perguruan Tinggi (BAN-PT), masa tunggu lulusan untuk bekerja dengan waktu kurang dari tiga bulan dinyatakan sangat baik. Cara lulusan memperoleh pekerjaan lebih banyak dari relasi atau teman dan pada umumnya lulusan PTB masih berstatus pegawai tidak tetap. Penghasilan perbulan yang diperoleh sekitar Rp. 4.500.000.
Dari hasil penelitian kepada penguna lulusan menyatakan kepuasan pengguna lulusan ada dilevel "Tinggi" pada kompetensi kepribadian dan kompetensi profesional. Hal ini tidak sejalan dengan hasil penelitian Oke (2012) yang menyatakan bahwa kompetensi profesional lulusan "Rendah" sehingga pengguna lulusan tidak puas. Menurut Permendikbud (2007) Kompetensi kepribadian adalah kemampuan personal yang mencerminkan kepribadian yang mantap, stabil, dewasa, arif, berwibawa, menjadi teladan bagi peserta didik, berakhlak mulia. Sedangkan kompetensi profesional adalah penguasaan materi pembelajaran secara luas dan mendalam, yang mencakup penguasaan materi kurikulum mata pelajaran disekolah dan subtasnsi keilmuan yang menaungi materinya, serta penguasaan terhadap struktur dan metedologi penelitian.

Selanjutnya untuk kompetensi pedagogik dan sosial, kepuasan pengguna lulusan ada dilevel "Rendah". Hal ini sejalan dengan hasil penelitian Mahendra (2012, pp. 1-20) yang menyatakan bahwa kompetensi pedagogik lulusan "Rendah" sehingga pengguna lulusan tidak puas. Menurut Permendikbud (2007) Kompetensi pedagogik adalah kemampuan pemahaman terhadap peserta didik, perancangan dan pelaksanaan pembelajaran, evaluasi hasil belajar, dan pengembangan peserta didik untuk mnegaktualisasikan berbagai potensi yang dimilikinya. Sedangkan kompetensi sosial adalah kemampuan guru untuk berkomunikasi dan bergaul secara efektif dengan peserta didik, tenaga kependidikan, orang tua/wali peserta didik, dan masyarakat sekitar.

Sesuai dengan KKNI lulusan yang bekerja dibidang kependidikan sebagai guru harus mempunyai standar kemampuan kerja yang berada di level kualifikasi 6 (Sarjana). Menurut Kerangka Kualifikasi Nasional Indonesia (KKNI) yaitu mampu mengaplikasikan, mengkaji, membuat desain, memanfaatkan IPTEKS, menyelesaikan masalah. Sedangkan menurut tingkat penguasaan pengetahuan sesuai Standar Isi Pembelajaran dalam KKNI 
mampu menguasai konsep teoritis bidang pengetahuan dan keterampilan tertentu secara umum dan konsep teoritis bagian khusus dalam bidang pengetahuan dan keterampilan tersebut secara mendalam.

Keterampilan umum yang harus dimiliki lulusan perguruan tinggi yang berada dilevel sarjana yaitu: 1) mampu menerapkan pemikiran logis, kritis, sistematis, dan inovatif dalam konteks pengembangan atau implementasi ilmu pengetahuan dan teknologi yang memperhatikan dan menerapkan nilai humaniora yang sesuai dengan bidang keahliannya; 2) Mampu menunjukkan kinerja mandiri, bermutu, dan terukur; 3) mampu mengkaji implikasi pengembangan atau implementasi ilmu pengetahuan dan teknologi yang memperhatikan dan menerapkan nilai humaniora sesuai dengan keahliannya berdasarkan kaidah, tata cara dan etika ilmiah dalam rangka menghasilkan solusi, gagasan, desain atau kritik seni; 4) Mampu menyusun deskripsi saintifik hasil kajian tersebut di atas dalam bentuk skripsi atau laporan tugas akhir, dan mengunggahnya dalam laman perguruan tinggi; 5) mampu mengambil keputusan secara tepat dalam konteks penyelesaian masalah di bidang keahliannya, berdasarkan hasil analisis informasi dan data; 6) mampu memelihara dan mengembangkan jaringan kerja dengan pembimbing, kolega, sejawat baik di dalam maupun di luar lembaganya. 7) mampu bertanggung jawab atas pencapaian hasil kerja kelompok dan melakukan supervisi serta evaluasi terhadap penyelesaian pekerjaan yang ditugaskan kepada pekerja yang berada di bawah tanggung jawabnya; 8) mampu melakukan proses evaluasi diri terhadap kelompok kerja yang berada di bawah tanggung jawabnya, dan mampu mengelola pembelajaran secara mandiri; 9) mampu mendokumentasikan, menyimpan, meng-amankan, dan menemukan kembali data untuk menjamin kesahihan dan mencegah plagiasi.

\section{Simpulan}

Berdasarkan hasil penelitian Studi Kepuasan Pengguna Lulusan Program Studi Pendidikan Teknik Bangunan Universitas Negeri Jakarta di Bidang Kependidikan, maka dapat disimpulkan pada tingkat kepuasan pengguna lulusan berada dalam kategori tinggi pada kompetensi kepribadian dan kompetensi profesional, atau dengan kata lain pengguna lulusan puas dengan kinerja lulusan PTB UNJ pada kompetensi kepribadian dan kompetensi profesional. Sementara itu tingkat kepuasan pengguna lulusan berada dalam kategori rendah pada kompetensi pedagogik dan kompetensi sosial, atau dengan kata lain pengguna lulusan belum merasa puas dengan kompetensi pedagogik dan kompetensi sosial.

\section{Daftar Pustaka}

Agustin, I. (2017). Analisis Keteserapan Lulusan Program Studi Pendidikan Teknik Bangunan Fakultas Teknik Universitas Negeri Jakarta Di Lapangan Pekerjaan. Jurnal Pensil 6(2), 1-5.

Alma, B. (2009). Manajemen Pemasaran dan Pemasaran Jasa. Bandung: Alpabeta.

Depdiknas. (2005). Undang-Undang Republike Indonesia Nomor 14 Tabun 2005 tentang Guru dan Dosen.

Hodges, D., \& Burchell, N. (2003). Business Graduate Competencies: Employers' Views on Importance and Performance. Asia-Pacific Journal of Cooperative Education 4(2), 16-22.

Kementerian Riset, Teknologi, dan Pendidikan. (2015). Pedoman Akademik Universitas Negeri Jakarta 2015/2016 Fakultas Teknik. (FT) Universitas Negeri Jakarta. Jakarta: Universitas Negeri Jakarta.

Mahendra, O. (2012). Studi Kepuasan Pengguna Lulusan Program Studi Pendidikan Teknik Bangunan Jurusan 
Teknik Sipil FT UNJ. Jurnal Pensil 1(1), $1-20$.

Nasution, S. (2014). Metode Research (Penelitian Ilmiah). Jakarta: Bumi Aksara.

Permendikbud. (2007). Permendikbud Nomor 16 tahun 2007 tentang Standar Kualifikasi Akademik dan Kompetensi Guru.

Peratuan Presiden. (2012). Peraturan Presiden No. 8 Tabun 2012 tentang Kerangka Kualifikasi Nasional Indonesia (KKNI).

Sari, R. (2015). Studi Penelusuran (Tracer Study) Lulusan Program Studi
Pendidikan Teknik Bangunan FT UNJ Tahun Lulusan 2006-2011. Jurnal Pensil 4(2), 79-84.

Sugiyono. (2012). Metode Penelitian Pendidikan: Pendekatan Kuantitatif, Kualitatif, dan R\&D. Bandung: Alfabeta.

Wahyudi, I. (2012). Mengajar Profesionalisme Guru Strategi Praktis mewnjudkan Citra Guru Profesional. Jakarta: Prestasi Jakarta. 